\title{
Conservative treatment of fibroids
}

\author{
Olav Istre
}

Received: 15 February 2007 / Accepted: 28 April 2007 / Published online: 1 June 2007

(C) Springer-Verlag 2007

Keywords Fibroids · Uterine artery · Laparoscopy · Embolisation $\cdot$ Hysteroscopy

\section{Introduction}

Incidence

Fibroids are the most common benign uterine tumours with an incidence range of $5.4-77 \%$ in women of reproductive age depending on the method of diagnosis [1]. They increase in incidence towards the end of a woman's reproductive life. They are particularly common in black populations with a nine-fold increase compared to Caucasian populations $[2,3]$. Some familial tendencies have been identified [4]. The aetiology of fibroids is unknown, although fibroid growth is oestrogen dependent. It is estimated that $50 \%$ of fibroids are asymptomatic and are an incidental finding at the time of clinical or ultrasound examination. Approximately $0.1 \%$ of fibroids present as sarcomatous fibroid which is a rare but serious smooth-muscle malignant tumour [5]. Submucosal fibroids or intramural fibroids in close relation to the uterine cavity are found in $40 \%$ of patients with heavy and/or prolonged menstrual bleeding [6-9].

The goal for therapy of fibroids and debilitating menorrhagia must take into consideration the needs and desires of the patient in terms of her lifestyle (e.g., days lost from work because of symptoms) and childbearing plans.

\section{O. Istre $(\bowtie)$}

Department of Gynecology and Obstetrics, Endoscopic Unit, Ullevaal University Hospital,

Kirkeveien 166,

N-0407 Oslo, Norway

e-mail: post@oistre.com
Hysterectomy has been regarded as the definitive surgical treatment for fibroids and has been a very commonly performed operation [10]. However, hysterectomy continues to be financially costly with billions of dollars spent annually, as well as costly in more fundamental terms of morbidity and mortality when compared with the less invasive alternatives of myomectomy, ablation, and myolysis [11-13]. Myomectomy involves the shelling out of fibroids from the myometrium, and in the case of submucosal fibroids, these can be removed surgically via hysteroscopic procedures [14]. Although morbidity is reduced with endoscopic surgery, this technique is not widely available and has limitations.

\section{Fibroid vascular supply}

The uterus has a very rich blood supply through two extrinsic arterial systems, the uterine and ovarian arteries. Intrinsic uterine arteries consist of ascending uterine, arcuate, radial, and peripheral arteries imply free flow through the uterus. Fibroids receive their blood supply from the intrinsic arteries, primarily from branches of arcuate arteries, and the vessels are located in the pseudocapsule around the fibroid. The ipsilateral uterine and ovarian arteries are connected by a communicating branch. In addition to its primary (uterine artery) and secondary (ovarian artery) extrinsic blood supply, the uterus enjoys a vast network of lesser known arterial collaterals [15]. If the blood supply from the right or left uterine artery is occluded, blood from the left or right artery will supply the myometrium via communications through arcuate arteries. Finally, if both uterine arteries are occluded, blood flow to the myometrium will develop from anastomoses with ovarian arteries. In addition to the primary and secondary blood flow, the uterus has a vast network of 
collateral arterial communications from the aorta external iliac and femoral artery branch [16].

To occlude primary blood flow, uterine artery occlusion must be more distal than the internal iliac artery, in case occlusion of both internal iliac arteries does not stop antegrade blood flow [17], and subsequently it does not cause uterine ischemia, and the Doppler flow remains unchanged after bilateral internal iliac artery ligation [18]. When bilateral internal iliac occlusion is performed distal to the posterior division, reverse flow in the middle hemorrhoidal artery reconstitutes antegrade flow in each uterine artery. Under these conditions, the antegrade flow in each uterine artery persists and pulse pressure is damped, resembling a venous system instead of an arterial system; consequently, it does not cause uterine ischemia.

\section{Therapy}

\section{Medicinal}

Progestational agents have been reported to have an influence on myoma growth and have a direct anti-oestrogenic effect at the cellular level [19].

In an open observational study, the effectiveness of a levonorgestrel-releasing intrauterine device (LNG-IUD) in the treatment of myoma-related menorrhagia was studied. In conclusion, this study demonstrated the clinical effectiveness of LNG-IUD in the treatment of myoma-related menorrhagia [20].

\section{Mifepristone}

A total of 166 women with symptomatic uterine myoma received 5-50 mg/day of mifepristone for 3-6 months, and daily treatment with all doses of mifepristone resulted in reductions in uterine and leiomyoma volumes ranging from $27-49 \%$ and $26-74 \%$, respectively. Mifepristone treatment reduced the prevalence and severity of dysmenorrhea, menorrhagia, and pelvic pressure, and the rates of amenorrhea ranged from $63-100 \%$. A notable adverse effect of mifepristone was development of endometrial hyperplasia [21].

In another study, the response of uterine leiomyomata to three daily doses of RU486 (5, 25, and $50 \mathrm{mg})$ was tested, and the effective dose to cause a clinically significant (50\%) decrease in leiomyoma volume appears to be $25 \mathrm{mg}$ daily [22].

\section{GnRH agonists}

Gonadotrophin-releasing hormone $(\mathrm{GnRH})$ agonists are widely used in the treatment of women with symptomatic myomas. The effectiveness of this treatment, as far as symptoms are concerned, is well established, and in recent years many studies have contributed to defining the optimum role for GnRH agonists. Side effects and health risks prohibit the long-term use of these compounds. The combined use of high-dose agonists and steroids in the so-called add-back schedules reduces many of the disadvantages of the monotherapy. However, it is still an expensive alternative when compared with definitive surgery, and therefore should only be used in women who insist on preservation of the uterus. Low-dose agonist therapy ('draw back') has not yet been proven to be suitable for clinical application. The use of GnRH agonists and steroids in sequential schedules seems to result in a loss of both the volume reduction as well as the reduction in clinical symptoms.

The use of GnRH agonists prior to myoma surgery should not become a routine measure and should be limited to cases where the size of the uterus is $>600 \mathrm{ml}$. Hysterectomy should only be preceded by GnRH agonist treatment if uterine volume decrease is expected to facilitate either the abdominal or vaginal procedure. For both operative procedures, the presence of myoma-related anaemia is an indication for pretreatment [23]. The use of GnRH agonists before endoscopic surgery is widely accepted on the basis of assumed advantages; however, definite proof of these advantages is not yet available [24]. It is, however, known that fibroids tend to return to their pretreatment size about 6 months after discontinuing treatment. GnRH agonist treatment cannot be continued indefinitely due to its potential complications and high cost. Experience with presurgical GnRH agonist use may indicate a treatment advantage, and the use of GnRH agonists as adjuncts to surgery is well established [25].

Twenty-seven women with uterine leiomyomas were treated with a standard dose of triptorelin for 8 weeks. Patients were then randomised to use 100,20 , or $5 \mu \mathrm{g}$ of triptorelin until week 26 . Uterine and myoma size, pituitaryovarian function, bone metabolism, and bone mineral density were monitored. During standard treatment, uterine size was reduced to $67.1 \%$ of baseline. During randomised treatment, uterine size was further reduced to $57.8 \%$ of baseline. There were no differences in overall volume reduction among the groups. Bone mineral density decreased significantly in the highest-dose group at week 26 . This study shows that the beneficial effects of initial high-dose agonist treatment on uterine leiomyomas can be preserved by continued low-dose treatment. Bone mineral density does not seem to change during reduced-dose agonist treatment [26].

Asoprisnil (Schering, TAP Pharmaceutical Products) is a novel, orally active, selective progesterone receptor modulator (SPRM) developed for the treatment of uterine 
fibroids and is now under clinical investigation in large phase III trials.

\section{Fibroid myolysis}

Myoma coagulation or myolysis with the laparoscope or hysteroscope is a valuable addition to the armamentarium of treatments for a problem that remains pervasive among women. Likewise, surgical techniques include the use of the Nd:YAG laser as well as the bipolar needle. The addition of myolysis to earlier uterine-sparing endometrial ablation or resection markedly improves the success rate of these minimally invasive alternatives to hysterectomy [11]. Myoma coagulation, when combined with endometrial ablation among women with symptomatic fibroids and bleeding, also reduces all subsequent surgery rates compared with endometrial ablation alone [11].

Power colour-Doppler imaging was performed preoperatively and postoperatively to determine the effectiveness of cryomyolysis (a freezing probe inserted into the fibroid controlled with ultrasound) in reducing or eliminating the primary blood supply as well as regression of the myomas. Myomas regressed up to $80 \%$, and major blood supply to the myomas was eliminated [27].

Cryomyolysis is able to maintain (or slightly reduce) the uterine fibroid at its post-GnRH agonist size, whereas all other uterine tissues return to pre-treatment size [28].

In case of pregnancy after myolysis, caution and intensive surveillance of mother and foetus must be applied, and caesarean section should be performed at earliest signs and symptoms of uterine rupture and at term before onset of labour [29].

Laparoscopic myomectomy and hysteroscopic myomectomy

In recent years, the endoscopic minimally invasive approach has significantly improved the quality and increased the options of treatment of fibroids.

Results from randomised trials and clinical series have shown that laparoscopic myomectomy provides the advantages of shorter hospitalisation, faster recovery, fewer adhesions, and less blood loss than abdominal myomectomy when performed by skilled surgeons. Improvements in surgical instruments and techniques allow for safe removal and multilayer myometrial repair of multiple large intramural myomas. Randomised trials support the use of absorbable adhesion barriers to reduce adhesions, but there is no apparent benefit of presurgical use of GnRH agonists. Pregnancy outcomes have been good, and the risk of uterine rupture is very low when the myometrium is repaired appropriately.
Laparoscopic myomectomy is an appropriate alternative to abdominal myomectomy, hysterectomy, and uterine artery embolisation for some women [30].

Interference with the blood supply to the uterus

Nonsurgical treatments interfering with the blood supply to the uterus or the fibroids include uterine artery embolisation performed by an interventional radiologist or laparoscopic/ vaginal uterine artery occlusion by the gynaecologist [31].

\section{Uterine artery embolisation}

The use of transcatheter uterine artery embolisation (UAE) as a treatment for uterine fibroids represents a new approach to the management of this common problem $[32,33]$. In the presence of fibroids, arteriography of the uterine arteries shows these vessels as dilated and tortuous, and laterally one can confirm the hypervascular nature of the fibroid by noting the extensive network of intrinsic arteries within the fibroid. Once identified, the uterine arteries are selectively catheterised. An embolic agent, such as polyvinyl alcohol (PVA) particles measuring $350-500$ or $500-710 \mu \mathrm{m}$ in diameter, is injected directly into the uterine arteries to induce thrombosis. Both uterine arteries should be embolised because the arcuate arteries arising from them anastomose across the midline. It has been shown that fibroids will decrease in size and symptomatology [34], and hypervascular fibroids tended to decrease in size after treatment compared to more isovascular or hypovascular fibroids [35]. Uterine artery embolisation can produce a mean reduction of $29-51 \%$ in uterine volume at the time of the 3 -month review, with longer follow-up showing continued shrinkage and no regrowth [36].

This procedure is unfortunately not without complications [37]. The acute degenerative procedure can be very painful and infection can occur. Hysterectomy may again be required in the case of hemorrhage or severe tissue necrosis. Delivering fibroids or sections of fibroids may be a natural process after uterine artery embolisation, therefore it is essential to warn women about the possible risk of infectious symptoms such as heavy discharge and fever, and consequently close follow-up is essential. The spontaneous expulsion of fibroids occurs over several months resulting in a significant reduction in menstrual loss and dysmenorrhea. Adequate antibiotic cover may be necessary to prevent sepsis [38]. A long-term side effect could be premature ovarian failure secondary to interference with the ovarian blood supply. In most studies, ovarian failure after UAE was found to occur most often in women in their late $40 \mathrm{~s}$, with an overall incidence of 5\% [34]. Although UAE 
is recognised for the treatment of fibroids and associated infertility, it is currently controversial which treatment modality has the greatest efficacy with regard to posttreatment pregnancy rates and also lowest side-effect profile.

\section{Uterine artery occlusion}

Laparoscopic bipolar coagulation of uterine arteries and anastomotic sites of uterine arteries with ovarian arteries represents another modality of avoiding hysterectomy in women with symptomatic fibroids [39, 40]. The peritoneum overlying the external iliac artery is incised with a $\mathrm{T}$ incision between the round ligament and the infundibulopelvic ligament. The iliac vessels are identified, and the retroperitoneal space is developed. The uterine artery is occluded with an endoclip at the level of the internal iliac artery. An identical procedure is performed on the ipsilateral side. The collateral arteries between ovaries and uterus (in the uteroovarial ligament) are coagulated using bipolar forceps.

In our institution, we studied 46 premenopausal women with symptomatic uterine fibroids undergoing radiological embolisation $(n=24)$ or laparoscopic closure of the uterine arteries $(n=22)$ [41, 42]. The laparoscopic technique reduced picture blood assessment score after 6 months by $50 \%$ in both groups. Uterus volume was reduced by $35-$ $40 \%$ in both groups. We found that laparoscopic occlusion of uterine vessels is a promising new method for treating fibroid-related symptoms, with less postoperative pain than embolisation and comparable effects on symptoms.

The effect of the temporary artery uterine clamp was first demonstrated in our institution in 2004, when a 43-year-old woman with menorrhagia, dysmenorrhea and pelvic pain of several years' duration with a uterus enlarged by fibroids to the size of a 16-week pregnancy was treated [43]. Her uterine arteries were non-invasively identified transvaginally and occluded for $6 \mathrm{~h}$ with a clamp that was guided by audible Doppler ultrasound. Following removal of the clamp, blood flow in the uterine arteries returned immediately. Three months after treatment, the uterine volume had decreased by $49 \%$ and the dominant fibroid volume by $54 \%$. Even though fibroidrelated symptoms may effectively be relieved by interference with the blood supply to the uterus, there seems to be no substantial effect in patients with dysfunctional bleeding.

\section{Application of conservative techniques}

\section{Infertility}

Myomectomy has significant associated risks to the woman and her future fertility. These include massive intra-operative hemorrhage, risk of emergency hysterectomy and disfigurement of the uterine cavity. In addition, the scar left on the uterus after myomectomy increases the chance of uterine rupture in future pregnancies. The association between fibroids and infertility has long been recognised [44]. It is accepted that there is an improved fertility outcome after myomectomy [45]. Many women do not wish to undergo an operative procedure as they may not accept the associated risks of an operation, and due to these circumstances, prefer even less invasive procedures such as UAE.

To determine the effect of myomectomy as a therapy for infertility and to define the factors that influence reproductive outcome, a retrospective study of a case series is summarised. To assess the role of leiomyomas and their surgical removal on pregnancy rates, 212 women who were investigated for infertility were studied. Patients were divided according to case control criteria as those who underwent laparoscopic removal of myomas (106) and those who did not (106); both groups were compared with 106 women with unexplained infertility without myomas. Of the 318 women, $83(26 \%)$ became pregnant and delivered live infants. The $44(42 \%)$ who underwent surgical removal of leiomyomas had higher delivery rates than $12(11 \%)$ who did not undergo surgery $(P<0.001)$ and $27(25 \%)$ who did not have myomas $(P<0.001)$. Patients whose myomas were not surgically treated had fewer deliveries than women who did not have myomas (12 vs. $27, P<0.002$ ). Fifteen women had spontaneous abortions before week 12: 3 (3\%) who had surgery, $10(9 \%)$ who did not have surgery, and $2(2 \%)$ who did not have myomas. The conclusion of this study emphasised that myomectomy improved pregnancy rates over nonsurgical management of myomas [46].

To determine the effects of hysteroscopic myomectomy on menorrhagia and infertility, the long-term outcomes of 108 women who underwent hysteroscopic resection of submucosal $(n=54)$, sessile $(n=30)$, or intramural $(n=24)$ leiomyomas over 7 years were investigated [47, 48]. After a mean follow-up of 41 months, myomas recurred in 27 subjects, with a 3 -year cumulative rate of $34 \%$. Twenty women had recurrent menorrhagia, with a 3 -year cumulative probability of $30 \%$. The 3 -year cumulative probability of conception was $49 \%$ in women with pedunculated lesions, $36 \%$ in those with sessile lesions, and 33\% in those with intramural lesions. Hysteroscopic resection of submucosal myomas gives satisfactory menorrhagia control and limited recurrence and shows beneficial effect for infertility.

\section{Pregnancy outcome}

Another retrospective study was conducted to establish the impact of myomectomy on pregnancy outcome with particular reference to its effect on the incidence of pregnancy loss [49]. Myomectomy was performed using microsurgical procedures on 51 women who had intramural or subserosal fibroids and wished to conceive. Overall, the conception 
rate following myomectomy was $57 \%$. Multiple regression analysis showed that age was the only factor which influenced conception rate; there was no instance of premature labour or scar rupture among 25 live births. This retrospective study suggests that myomectomy for intramural and subserosal fibroids may significantly improve the reproductive performance of women presenting with infertility or pregnancy loss.

To compare pregnancy outcomes in women with fibroids who were treated with UAE with those treated with laparoscopic myomectomy, data from 53 pregnancies after $\mathrm{UAE}$ and 139 pregnancies after laparoscopic myomectomy were analysed. Pregnancies after UAE had higher rates of preterm delivery (odds ratio 6.2; 95\% CI 1.4-27.7) and malpresentation (odds ratio $4.3 ; 95 \%$ CI $1.0-20.5$ ) than did pregnancies after laparoscopic myomectomy. The risks of post-partum hemorrhage (odds ratio $6.3 ; 95 \%$ CI $0.6-71.8$ ) and spontaneous abortion (odds ratio $1.7 ; 95 \%$ CI $0.8-3.9$ ) after UAE were similarly higher than the risks after laparoscopic myomectomy; however, these differences were not statistically significant. Pregnancies in women with fibroids who were treated by UAE compared with pregnancies after laparoscopic myomectomy were at increased risk for preterm delivery and malpresentation [50].

\section{Conclusions}

Fibroids present with a variety of symptoms including infertility, bleeding problems, pressure and pain. They may be single or multiple, occur at different ages, and they require individualised treatment approaches.

In infertility patients, single fibroids should be removed; with multiple fibroids, medical or circulation therapy might be the only option for saving the uterus. For bleeding problems, an important issue is the location of the fibroid, in case of submucosal or type 0 , hysteroscopic resection is the method of choice.

For the bigger intramural, subserosal and even multiple fibroids, uterine artery therapy with embolisation or laparoscopy seems to achieve good results for both bleeding problems and pressure symptoms.

Both radiological and laparoscopic occlusion techniques are potential treatment options. However both techniques require a high level of skill and should be confined to special centres with appropriate expertise. Complication rates are significant, but similar for the two procedures. Counselling of patients is of importance.

\section{References}

1. Lethaby A, Vollenhoven B (2002) Fibroids (uterine myomatosis, leiomyomas). Clin Evid Jun(7):1666-1678
2. Kjerulff KH, Guzinski GM, Langenberg PW, Stolley PD, Moye NE, Kazandjian VA (1993) Hysterectomy and race. Obstet Gynecol 82:757-764

3. Kjerulff KH, Langenberg P, Seidman JD, Stolley PD, Guzinski GM (1996) Uterine leiomyomas. Racial differences in severity, symptoms and age at diagnosis. J Reprod Med 41:483-490

4. Luoto R, Kaprio J, Rutanen EM, Taipale P, Perola M, Koskenvuo M (2000) Heritability and risk factors of uterine fibroids-the Finnish Twin Cohort study. Maturitas 37:15-26

5. Parker WH, Fu YS, Berek JS (1994) Uterine sarcoma in patients operated on for presumed leiomyoma and rapidly growing leiomyoma. Obstet Gynecol 83:414-418

6. Dodson MG (1994) Use of transvaginal ultrasound in diagnosing the etiology of menometrorrhagia. J Reprod Med 39:362-372

7. Gimpelson RJ, Whalen TR (1995) Hysteroscopy as gold standard for evaluation of abnormal uterine bleeding. Am J Obstet Gynecol 173:1637-1638

8. Gimpelson RJ (1992) Office hysteroscopy. Clin Obstet Gynecol 35:270-281

9. Fraser IS (1990) Hysteroscopy and laparoscopy in women with menorrhagia. Am J Obstet Gynecol 162:1264-1269

10. Farquhar CM, Steiner CA (2002) Hysterectomy rates in the United States 1990-1997. Obstet Gynecol 99:229-234

11. Goldfarb HA (2000) Myoma coagulation (myolysis). Obstet Gynecol Clin North Am 27:421-430

12. Guarnaccia MM, Rein MS (2001) Traditional surgical approaches to uterine fibroids: abdominal myomectomy and hysterectomy. Clin Obstet Gynecol 44:385-400

13. Dicker RC, Greenspan JR, Strauss LT et al (1982) Complications of abdominal and vaginal hysterectomy among women of reproductive age in the United States. The collaborative review of sterilization. Am J Obstet Gynecol 144:841-848

14. Fernandez H, Sefrioui O, Virelizier C, Gervaise A, Gomel V, Frydman R (2001) Hysteroscopic resection of submucosal myomas in patients with infertility. Hum Reprod 16:1489-1492

15. Burbank F, Hutchins FL Jr (2000) Uterine artery occlusion by embolization or surgery for the treatment of fibroids: a unifying hypothesis-transient uterine ischemia. J Am Assoc Gynecol Laparosc 7:S1-S49

16. Chait A, Moltz A, Nelson JH Jr (1968) The collateral arterial circulation in the pelvis. An angiographic study. Am J Roentgenol Radium Ther Nucl Med 102:392-400

17. Burchell RC (1968) Physiology of internal iliac artery ligationJ Obstet Gynaecol Br Commonw 75:642-651

18. Chitrit Y, Guillaumin D, Caubel P, Herrero R (2000) Absence of flow velocity waveform changes in uterine arteries after bilateral internal iliac artery ligation. Am J Obstet Gynecol 182:727-728

19. Tiltman AJ (1985) The effect of progestins on the mitotic activity of uterine fibromyomas. Int J Gynecol Pathol 4:89-96

20. Mercorio F, De Simone R, Di Spiezio SA et al (2003) The effect of a levonorgestrel-releasing intrauterine device in the treatment of myoma-related menorrhagia. Contraception 67:277-280

21. Steinauer J, Pritts EA, Jackson R, Jacoby AF (2004) Systematic review of mifepristone for the treatment of uterine leiomyomata. Obstet Gynecol 103:1331-1336

22. Murphy AA, Morales AJ, Kettel LM, Yen SS (1995) Regression of uterine leiomyomata to the antiprogesterone RU486: doseresponse effect. Fertil Steril 64:187-190

23. Lethaby A, Vollenhoven B, Sowter M (2001) Pre-operative GnRH analogue therapy before hysterectomy or myomectomy for uterine fibroids. Cochrane Database Syst Rev CD000547 DOI 10.1002/ 14651858.CD000547

24. Broekmans FJ (1996) GnRH agonists and uterine leiomyomas. Hum Reprod 11(Suppl 3):3-25

25. Golan A (1996) GnRH analogues in the treatment of uterine fibroids. Hum Reprod 11(Suppl 3):33-41 
26. Broekmans FJ, Hompes PG, Heitbrink MA et al (1996) Two-step gonadotropin-releasing hormone agonist treatment of uterine leiomyomas: standard-dose therapy followed by reduced-dose therapy. Am J Obstet Gynecol 175:1208-1216

27. Zupi E, Piredda A, Marconi D et al (2004) Directed laparoscopic cryomyolysis: a possible alternative to myomectomy and/or hysterectomy for symptomatic leiomyomas. Am J Obstet Gynecol 190:639-643

28. Olive DL, Rutherford T, Zreik T, Palter S (1996) Cryomyolysis in the conservative treatment of uterine fibroids. J Am Assoc Gynecol Laparose 3:S36

29. Vilos GA, Daly LJ, Tse BM (1998) Pregnancy outcome after laparoscopic electromyolysis. J Am Assoc Gynecol Laparosc 5: 289-292

30. Hurst BS, Matthews ML, Marshburn PB (2005) Laparoscopic myomectomy for symptomatic uterine myomas. Fertil Steril 83:1-23

31. Istre $O$ (2005) Uterine artery occlusion for the treatment of symptomatic fibroids: endoscopic, radiological and vaginal approach. Minim Invasive Ther Allied Technol 14:167-174

32. Ankum WM, Reekers JA (2001) Embolization of uterine artery: a new treatment for uterine myomas. Ned Tijdschr Geneeskd 145:765-769

33. Garcia MJ, Gheyi VK, Uppot RN, Nowakowski FS, Storm ES (2000) Uterine fibroids: primary treatment with therapeutic embolization. Del Med J 72:397-401

34. Lumsden MA (2002) Embolization versus myomectomy versus hysterectomy: which is best, when? Hum Reprod 17:253-259

35. Fleischer AC, Donnelly EF, Campbell MG, Mazer MJ, Grippo D, Lipsitz NL (2000) Three-dimensional color Doppler sonography before and after fibroid embolization. J Ultrasound Med 19:701-705

36. Hutchins FL Jr, Worthington-Kirsch R (2000) Embolotherapy for myoma-induced menorrhagia. Obstet Gynecol Clin North Am 27:397-405, viii

37. Godfrey CD, Zbella EA (2001) Uterine necrosis after uterine artery embolization for leiomyoma. Obstet Gynecol 98:950-952

38. Laverge F, D’Angelo A, Davies NJ, Wood A, Amso NN (2003) Spontaneous expulsion of three large fibroids after uterine artery embolization. Fertil Steril 80:450-452
39. Liu WM (2000) Laparoscopic bipolar coagulation of uterine vessels to treat symptomatic leiomyomas. J Am Assoc Gynecol Laparosc 7:125-129

40. Liu WM, Ng HT, Wu YC, Yen YK, Yuan CC (2001) Laparoscopic bipolar coagulation of uterine vessels: a new method for treating symptomatic fibroids. Fertil Steril 75:417-422

41. Hald K, Langebrekke A, Klow NE, Noreng HJ, Berge AB, Istre O (2004) Laparoscopic occlusion of uterine vessels for the treatment of symptomatic fibroids: initial experience and comparison to uterine artery embolization. Am J Obstet Gynecol 190:37-43

42. Hald K, Klow NE, Qvigstad E, Istre O (2007) Laparoscopic occlusion compared with embolization of uterine vessels: a randomized controlled trial. Obstet Gynecol 109:20-27

43. Istre O, Hald K, Qvigstad E (2004) Multiple myomas treated with a temporary, noninvasive, Doppler-directed, transvaginal uterine artery clamp. J Am Assoc Gynecol Laparosc 11:273-276

44. Benson CB, Chow JS, Chang-Lee W, Hill JA III, Doubilet PM (2001) Outcome of pregnancies in women with uterine leiomyomas identified by sonography in the first trimester. J Clin Ultrasound 29:261-264

45. Dubuisson JB, Chapron C, Chavet X, Gregorakis SS (1996) Fertility after laparoscopic myomectomy of large intramural myomas: preliminary results. Hum Reprod 11:518-522

46. Bulletti C, De ZD, Polli V, Flamigni C (1999) The role of leiomyomas in infertility. J Am Assoc Gynecol Laparosc 6:441-445

47. Vercellini P, Zaina B, Yaylayan L, Pisacreta A, De Giorgi O, Crosignani PG (1999) Hysteroscopic myomectomy: long-term effects on menstrual pattern and fertility. Obstet Gynecol 94:341-347

48. Vercellini P, Maddalena S, De Giorgi O, Pesole A, Ferrari L, Crosignani PG (1999) Determinants of reproductive outcome after abdominal myomectomy for infertility. Fertil Steril 72:109-114

49. Li TC, Mortimer R, Cooke ID (1999) Myomectomy: a retrospective study to examine reproductive performance before and after surgery. Hum Reprod 14:1735-1740

50. Goldberg J, Pereira L, Berghella V et al (2004) Pregnancy outcomes after treatment for fibromyomata: uterine artery embolization versus laparoscopic myomectomy. Am J Obstet Gynecol 191:18-21 